Journal of Social Sciences 4 (4): 320-328, 2008

ISSN 1549-3652

(C) 2008 Science Publications

\title{
The Effects of Personality and Cultural Intelligence on International Assignment Effectiveness: A Review
}

\author{
${ }^{1}$ Naresh Kumar, ${ }^{1}$ Raduan Che Rose and ${ }^{2}$ Subramaniam \\ ${ }^{1}$ Faculty of Economics and Management, University Putra Malaysia, \\ ${ }^{2}$ Graduate School of Management, Universiti Putra Malaysia
}

\begin{abstract}
Problem statement: Studies on cultural intelligence (CQ) have been recently initiated dramatically in an effort to determine how they were related to positive life outcomes. While past findings showed positive correlations to various aspects of life outcomes, clear establishments of the theoretical and empirical connections of CQ on cross-cultural adjustment and job performance among expatriates was still remain elusive in the literature. Approach: The literature was explored to acknowledge the accessible relationships among CQ, cultural adjustment and job performance of expatriates. Results: This article proposes a research framework that intends to cover several gaps and weaknesses identified in the literature. The sway of personality traits on CQ and expatriate assignment effectiveness were also discussed. In offering a new research approaches, total of eight research propositions were established. Conclusions/Recommendations: This article provides an updated review of the literature on CQ. The practical implications as well as academic contributions were also presented. Thus, anticipate more empirical studies on CQ and at the same time substantiate the proposed research framework.
\end{abstract}

Key words: Personality traits, cultural intelligence, expatriate adjustment, job performance

\section{INTRODUCTION}

Globalization is quickly becoming a permanent fixture in today's business environment. Accordingly, the effectiveness of international assignment is becoming important source for competitive advantage for many organizations. Prior research has indicated that cross-cultural adjustment played significant roles for effectiveness in the international assignment among the expatriates. Despite growing interest in the expatriate management, many gaps hang about in understanding the diverse factors affecting expatriate cross-cultural adjustment and job performance. It is believed that cultural intelligence (CQ) represents an essential intercultural capacity that is crucial for expatriates working on international assignments within the contemporary organizations. Yet, awareness of the CQ's significance for international assignment effectiveness still remains at an early stage. Responding to this need, this article highlights the theoretical based predictions for relationships between personality traits, $\mathrm{CQ}$ and cross-cultural effectiveness, specifically adjustment and job performance.

Theoretical development and propositions: The concept of CQ represents an individuals capability for successful adaptation to new and unfamiliar cultural settings and ability to function easily and effectively in situations characterized by cultural diversity ${ }^{[3,22]}$. CQ is composed of mental (meta-cognitive and cognitive), motivational and behavioral components. The mental component of CQ refers to the skills needed to conceptualize a new culture and develop patterns from cultural cues, meta-cognitive CQ relates to the processes used to acquire and understand cultural knowledge and cognitive CQ is general knowledge about culture and cultural differences. Motivational CQ goes beyond recognizing cultural differences and deals with the motivation behind cognitive processes and cognitive knowledge, it reflects the interest in engaging others and the desire to adapt to the other culture. Lastly, the behavioral aspect involves the capability to engage in adaptive behaviors in accordance with cognition and motivation.

Accordingly, because individuals higher in CQ can more easily navigate and understand unfamiliar cultures, theoretically, they are expected to be more effective during their international assignment. However, due perhaps to the relative newness of the CQ construct, even though it is sufficiently refined so that research is growing, theoretical development of the role CQ may play in expatriate adjustment and job performance has been limited. Moreover, it is still

Corresponding Author: Naresh Kumar, Faculty of Economics and Management, University Putra Malaysia. 
unclear whether or not different CQ dimensions are more important to the prediction of adjustment and job performance than others hence we examine the four dimensions separately in our proposed research framework. Since the four dimensions of $\mathrm{CQ}$ are qualitatively different facets of the overall capability to function and manage effectively in culturally diverse settings ${ }^{[22]}$, we focus on CQ as an aggregate multidimensional construct $^{[3]}$ when developing the theoretical framework and make specific propositions.

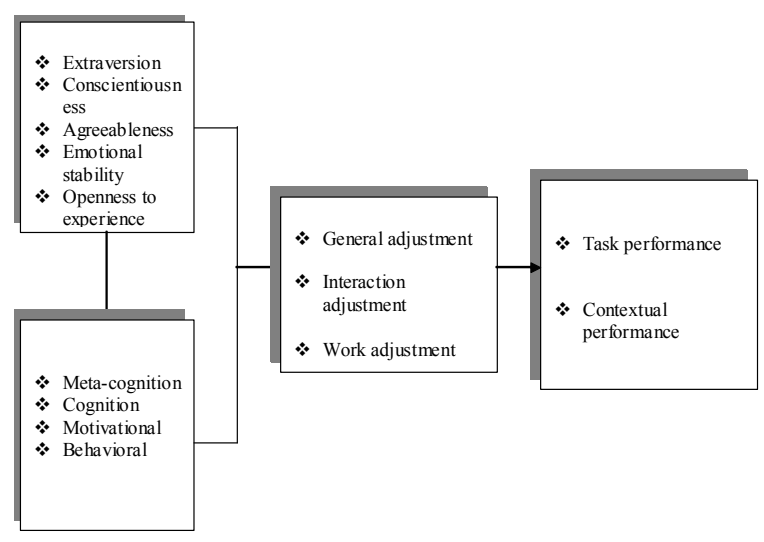

Fig. 1: A simplified theoretical framework

Another related gap exists in our knowledge of CQ construct. Although it is important to understand outcomes of $\mathrm{CQ}$, it is also important to examine antecedents of CQ. Unfortunately, given the novelty of the concept, it is not fully understood why some individuals might experience greater CQ than others. A diverse set of individual difference constructs could be related to $\mathrm{CQ}^{[1]}$. This examination advances the study by exploring the effects of personality traits on CQ. However, being the only study that examines the effects of personality traits on CQ and the use of unrepresented sample, for example the MBA students has triggers for new research in this area. In considering why some people are more culturally intelligent than others, it is useful to examine whether individual differences in personality traits predispose individuals to possess varying levels of CQ. Moreover, the existing expatriate literature has shown that personality differences often account for variations in expatriate cross-cultural adjustment and job performance ${ }^{[12,40,43,47,53]}$.

\section{MATERIALS AND METHODS}

In this article, we attempt to provide a comprehensive understanding of personality and CQ's contributions on international assignment effectiveness. For this purpose, a thorough search of journal articles, research studies, doctoral dissertations, World Wide Web (WWW) and books were done. Drawing on evolutionary personality psychology, social learning, social support, management stress and work-role transition theories, we developed a comprehensive model that encompasses the interrelationships among expatriate personality, CQ, expatriate adjustment and expatriate job performance (Fig. 1). Finally, we discuss the uniqueness of the CQ construct in relation to other non-academic intelligence (e.g., emotional intelligence and social intelligence) in explaining variance in expatriate cross-cultural adjustment and job performance. More specifically, our discussion was divided into eight sections and each section encompasses relevant literature to support the development of the framework as well as the research propositions.

\section{RESULTS}

After reviewing core aspects of personality and $\mathrm{CQ}$, the following propositions were formed in support of the simplified theoretical framework (Fig. 1).

1. Personality has significant influence on expatriate cultural intelligence.

2. Expatriate's personality has significant influence on expatriate cross-cultural adjustment.

3. Expatriate personality has significant influence on job performance.

4. Expatriate cultural intelligence has significant influence on cross-cultural adjustment.

5. Expatriate cultural intelligence has significant influence on job performance.

6. Expatriate adjustment has significant influence on job performance.

7. The relationship between $\mathrm{CQ}$, personality and expatriate job performance is mediated by expatriate cross-cultural adjustment.

8. CQ is distinct from, but positively correlates with EQ and SQ.

The eight propositions projected in this article could significantly facilitate new directions for future research. Indeed, all the propositions could be easily transformed into research hypotheses rather than as statistical hypotheses. For a basic explanation, a research hypothesis predicts the nature of the relationship being examined in rather general, nonquantitative terms; a statistical hypothesis is a translation of the research hypothesis in terms of the statistical parameters of the population being studied. 


\section{DISCUSSION}

The influence of personality on cultural intelligence: Prior research on individual differences has distinguished between trait-like constructs and statelike constructs ${ }^{[1]}$. Trait-like individual differences are not task specific or situation and are stable over time ${ }^{[18]}$, which is represent by personality traits in this study. In contrast, state-like individual differences are specific to certain tasks and situations and tend to be malleable over time (e.g., Bandura, 1977). According to ${ }^{[36]}$, traitlike individual differences are more indirect and serve as predictors of proximal state-like individual differences $^{[18]}$, which in this study represent by CQ. Thus, it is proposed that personality characteristics (trait-like individual differences that describe broad and stable predispositions) serve as predictors of CQ (statelike individual differences that describe malleable capabilities to interact effectively with people from different cultures).

According to evolutionary personality psychology, personality traits are universal adaptive mechanisms that have developed and evolved in humans over time as mental solutions to preserve life and reproduction ${ }^{[11]}$. These adaptive mechanisms include [personality characteristics such as] humans ability to learn hierarchies in society (extraversion) their willingness to cooperate (agreeableness) their capacity for reliable work and enduring commitment (conscientiousness) their ability to handle stress (neuroticism or emotional stability) and their propensity for innovation or astuteness in solving problems (openness or intellect ${ }^{[11,12]}$. In a similar vein, it was expected that since CQ involves the ability to effectively adapt to culturally diverse contexts (meta-cognitively, cognitively, motivationally and behaviorally) certain personality traits should be related to specific factors of CQ and certain personality traits should be able to predict and explain variance in levels of CQ among individuals. Van Dyne and Ang, ${ }^{[1]}$ has demonstrated that the four dimensions of CQ were distinct from and yet related to, more distal big five personality traits in conceptually meaningfully ways. In their study, openness to experience was the only big five personality that was significantly related to all four facets of CQ. Lee and Sukoco ${ }^{[43]}$ however, found that conscientiousness significantly predicts cognitive, motivational and behavioral component of $\mathrm{CQ}$.

The influence of personality on cross-cultural adjustment: Cross-cultural adjustment is conceptualized as the degree of psychological comfort an expatriate has with the various aspects of a host culture $^{[9,27]}$. Three specific areas of cross-cultural adjustment have been distinguished in the literature ${ }^{[9]}$ Adjustment to (1) general environment (degree of comfort with general living conditions, such as climate, health facilities and food) (2) interaction with host country nationals and (3) work (performance standards, job and supervisory responsibilities).

Social learning theory ${ }^{[5,12,52]}$, as applied to an expatriate context, suggests that uncertainty is reduced when expatriates learn appropriate behaviors through interaction with and observation of Host Country Nationals (HCNs). The theory typically proposes that the more HCNs the expatriate interacts with and the more diverse these contacts are, the greater the repertoire of acceptable behaviors he or she will have to draw on ${ }^{[12]}$, which in turn facilitates the cross-cultural adjustment $^{[48]}$. It also can be applied to expatriates personality-adjustment relationship: Certain personality traits predispose individuals to engage in interpersonal interaction with HCNs and learn about new culture, in turn it may lead to better cross-cultural adjustment. For instance $^{[12,50]}$, argue that expatriates with greater openness (receptivity to learn and change in the new situation) have a greater interest in the new culture, take more opportunities to learn about it from contacting host country nationals and adjust to the host country culture better than low openness expatriates.

Prior research on cross-cultural adjustment has demonstrated that personality traits such as conscientiousness, openness to experience, selfmonitoring and self efficacy, are important predictors of cross-cultural adjustment ${ }^{[12,30,47,49,50]}$. The effects of each dimension in the personality traits has somewhat different. Caligiuri ${ }^{[12]}$ contended that extroversion, agreeableness and emotional stability lead to willingness to stay (better adjustment). Ones and Viswesvaran $^{[47]}$ indicated that conscientiousness level of prospective expatriates lead to higher degree of expatriate adjustment.

The influence of personality on job performance: In recent years, emphasis on the big five superordinate factors of personality as the basic structure of personality $^{[17]}$ has triggered increasing interest in personality in the organizations ${ }^{[6]}$. While domestic studies involving the big five have demonstrated that some of these traits help to explain the variation in job performance ${ }^{[6,34]}$ only a handful of published studies have investigated the influence of the big five on expatriate job performance ${ }^{[12,20,21,47,53]}$. The findings on effects of each dimension in the personality traits has somewhat mixed. For instance, ${ }^{[53]}$ found that openness to experience was the only big five personality 
significantly predicts the contextual and task performance among the expatriates. However, ${ }^{[4]}$ found that openness to experience was not deemed to be one of the most important personality dimensions for job performance. Caligiuri ${ }^{[6]}$ found that conscientiousness is positively related to the supervisor-rated performance on the expatriate assignment. Caligiuri and Sinangil and Ones ${ }^{[14,55]}$ however, found that dependability (conscientiousness) is a poor predictor of overall job performance.

The big five personality characteristics should predict expatriate job performance based on the tenets of evolutionary personality psychology ${ }^{[1]}$. First, according to the theory of evolutionary personality psychology, the Big Five personality characteristics represent universal adaptive mechanisms that allow humans to adapt with and meet the demands of physical, social and cultural environments ${ }^{[11,44]}$. Second, while all individuals have some degree of these universal Big Five adaptive mechanisms, individuals vary in the extent to which they possess these personality characteristics necessary for success in goal attainment. Thus, those who possess key personality traits suited for a given role in a given physical or social environment will adapt and perform more effectively than those who do not possess the appropriate traits or personality characteristics for that same role. Likewise, from a socioanalytic perspective, Hogan and colleagues $^{[31,32,33,]}$ attempt to align personality with performance criteria has led to better prediction of performance outcomes.

The influence of cultural intelligence on crosscultural adjustment: We expect CQ to be related to cross-cultural adjustment based on stress management theory of psychological stress. Since intercultural interactions involves a series of stress-provoking life changes that draw on adjustive resources and require coping responses, cross-cultural adjustment, therefore, is conceptualized by successfully coping with change. Based on $^{[3]}$ analysis, certain $\mathrm{CQ}$ facets such as motivational and behavioral CQ are expected to negate psychological stress, thus leads to higher level of crosscultural adjustment. This is consistent with metaanalytic findings that self-efficacy and relationship skills predict expatriate adjustment $t^{[7]}$.

Motivational CQ should positively relate to crosscultural adjustment because those with higher motivational CQ have intrinsic interest in other cultures and expect to be successful in culturally diverse situations. According to social cognitive theory ${ }^{[2]}$ they initiate effort, persist in their efforts and perform better.
For instance ${ }^{[25]}$ demonstrated that higher efficacy beliefs led to engagement and persistence in difficult situations, as well as better adjustment. As for behavioral CQ, since cultural adjustment is a persons sense of psychological comfort and familiarity in a new environment, those with the capability to vary their behavior (behavioral CQ) should have higher cultural adjustment. According to ${ }^{[26]}$ theory of self-presentation, individuals use impression management techniques to so that others view them positively. Since cultures differ in their norms for appropriate behaviors ${ }^{[59]}$ the ability to display a flexible range of behaviors is critical to creating positive impressions and developing intercultural relationships ${ }^{[28]}$. When individuals are flexible, they are less offensive to others, more likely to fit in and better adjusted. As for meta-cognitive and cognitive CQ, we do not predict relationships with cultural adjustment because cognitive capabilities do not necessarily translate into actions and behaviors ${ }^{[29]}$.

Prior study has demonstrated that motivational and behavioral component of $\mathrm{CQ}$ are significant predictors of expatriate cross-cultural adjustment. For instance ${ }^{[3]}$ demonstrate the utility of motivational and behavioral CQ in predicting general adjustment among expatriates. Templer, Tay and Chandrasekar ${ }^{[58]}$ indicated that motivational CQ predicts all three facets of adjustment. They further demonstrate that motivational CQ adds incremental variance over and above cross-cultural interventions such as realistic living conditions and job preview, thereby highlighting the importance and utility of motivation CQ for the expatriate literature.

The influence of cultural intelligence on job performance: According to ${ }^{[15]}$ performance is a function of knowledge, skills, abilities and motivation directed at role-prescribed behavior, such as formal job responsibilities. From the performance appraisal standpoint, ones performance is evaluated based on the degree to which individuals meet role expectations ${ }^{[38]}$. Role expectations and perceptions of role expectations however, are influenced by cultural values. For instance $^{[56]}$ argued that individuals often receive poor performance evaluations when they have a different cultural background, do not understand cultural differences in role expectations and do not conform to role expectations. Since expectations for performing role prescribed behaviors often differ across cultures, it is proposed that all four dimensions of CQ will enhance cognitive understanding, motivation and behavioral enactment of role expectations.

Cognitive CQ may facilitate one to have more accurate understanding of role expectations. For example, those with rich mental representations of 
culturally-based social interactions are more aware of potential differences in role expectations and more likely to demonstrate appropriate role behaviors. Metacognitive CQ should also influence expatriate performance since those with high meta-cognitive CQ know when and how to apply their cultural knowledge. They do not rely on habitual knowledge structures, but select from multiple knowledge structures depending on the context. Accordingly, they have more accurate understanding of expected role behaviors in situations characterized by cultural diversity. Grounded with theories of motivation ${ }^{[24,37]}$, motivational CQ should also influence expatriate performance because the motivational states of CQ (namely, specific selfefficacy and intrinsic motivation in cross-cultural settings) can enhance the strength of an individual's persistent effort toward their task in different cultural contexts. Those with energy and persistence tend to practice new behaviors and through practice, improve their performance. Finally, behavioral CQ should also influence expatriate job performance. Those with high behavioral CQ tend to flexible in their verbal and nonverbal behaviors to meet expectations of others. When self-presentation ${ }^{[26]}$ parallels role expectations, misunderstandings should be lower and performance should be higher. Consistent with this ${ }^{[53]}$ demonstrated positive effects of behavioral flexibility on crosscultural performance. Being the only empirical evidence $^{[2,3]}$ demonstrated that meta-cognitive and behavioral CQ significantly predicts task performance among the expatriates.

The influence of cross-cultural adjustment on job performance: The proposed relationship between cross-cultural adjustment and job performance are also theoretically grounded based on stress management theory of psychological stress. International assignments represent a considerable challenge for expatriates because they may encounter cultural and instrumental barriers in different work and life environment. This may have significant impact on their mental well-being since poorly adjusted expatriates may be experiencing psychological stress. Within the stress research ${ }^{[19]}$ it has been suggested that maladjustment may hamper job performance by creating cognitive fatigue that deprives individuals of the energy needed to perform their jobs. In support of the negative relationship between psychological stress and performance ${ }^{[45]}$ found occupational stress to be negatively related to job performance. Vicino and Bass $^{[60]}$ also found that stress negatively correlated with managerial success. Similar arguments also can be applied to expatriates adjustment-performance relationship: successful cross-cultural adjustment in local culture reduces expatriates stress and strain, which, in turn may improve their performance by helping them to expend more energy and efforts on their work $^{[42]}$. For example ${ }^{[12]}$ posited that an expatriates inability to cope with the stress associated with adjusting to an overseas assignment may result in personal and professional withdrawal behaviors (e.g. depression, absence, turnover) and that these behaviors may inhibit performance. A considerable number of studies have indicated that expatriates psychological stress caused by maladjustment negatively affects their performance $^{[7,13,42,54,61]}$. Thus, based on stress management theories, it is expected that individuals who adjusted well to the work, interaction and general environment will be able to perform at higher levels.

Mediating effect of adjustment on personality, CQ and job performance relationships: A smooth transition across work assignments is critical to the effectiveness of expatriate assignment because the work-role expatriates execute in the host country may be quite new to them, even though the task is the same as in the their home country due to different cultural contexts ${ }^{[8,46]}$. According to work-role transition theory, adjustment to a new role and/or situation is fundamental to subsequent outcomes in the role ${ }^{[46]}$. Thus, adjustment is viewed as affecting other work-related outcomes such as strain, job satisfaction, organizational commitment, job performance and turnover intention $^{[30]}$. Accordingly, individual with a higher level of CQ will show better performance through a successful work transition to new international assignments because they are more capable of adapting effectively to a new cultural context. If competent individuals in a domestic setting cannot make a successful work transition to an international assignment, their performance will suffer. In a similar manner, those who possess key personality traits suited for a new role in an international context predispose individuals to perform more effectively in their job than those who do not possess the appropriate traits or personality characteristics for that same role by making appropriate work-role transition. Thus, CQ and personality traits especially those superiority striving personality (i.e., extraversion, openness to experience $)^{[50]}$ is a necessary but not sufficient component for expatriate performance, we posit that work adjustment mediates the relationship between expatriates CQ, personality and individual performance. Moreover, maladjustment in nonwork domains may negatively affect expatriates work adjustment and work-related attitudes and outcomes by creating 
psychological hardship ${ }^{[22,57]}$. As such, we also propose that maladjustment in interaction and general life also mediate the relationship between expatriates CQ, personality and individual job performance.

Previous expatriate research implies that adjustment might mediate the relationship between various individual differences and diverse expatriate assignment effectiveness ${ }^{[7,35,39]}$. Indeed, few researchers have examined the mediating role of cross-cultural adjustment ${ }^{[41,42,57]}$. While ${ }^{[12]}$ demonstrated a direct effect of conscientiousness on the supervisor-rated performance of expatriates based on evolutionary personality psychology, there was no attention paid to the underlying processes responsible for this relationship. In addition ${ }^{[53]}$ showed that work adjustment partially mediates two individual difference measures (i.e., intelligence and people orientation) and performance based on a post hoc analysis.

CQ's relationship with other form of intelligences: While CQ may have some overlapping with other related forms of non-academic intelligences, we argue that since CQ deals specifically with cognition, motivation and behavior in cross-cultural settings, the construct is theoretically and empirically distinct from emotional intelligence $(\mathrm{EQ})^{[51]}$ and social intelligence $(\mathrm{SQ})^{[16]}$. For example, even though meta-cognitive and behavioral CQ may be similar to EQ in the sense that they describe individual differences about how people may conform and be flexible according to situation demands and social cues, individuals who high in EQ but do not have cultural sensitivity may suffer from cross-cultural adaptation due to culturally inappropriate understanding and interpretation of culture-specific situational information. In addition ${ }^{[23]}$ argues that EQ does not include adaptation across cultures meanwhile CQ has a heavy emphasis on meta-cognitions, including thinking about thinking. They also argue that a person having a high emotional intelligence in their native culture may be entirely incapable at generalizing across cultural settings (p.105), however this statement has not been empirically tested.

As for SQ, it involves skills related to all social interactions and acting appropriately in these interactions, thus suggests a similarity to behavioral component of $\mathrm{CQ}$, which also reflects interpersonal competencies $^{[10]}$. However, does SQ necessarily translate into effective cross-cultural adjustment? The answer is unlikely, because rules for social interactions vary from culture to culture. As such, individuals who are able to interact effectively with others in a particular culture may not necessarily be able to do so in a different cultural environment characterized by a different set of social norms. CQ on the others hand is the ability to interact in culturally diverse settings ${ }^{[2]}$.

\section{CONCLUSION}

This article contributes to both CQ literature and the research on expatriate management in several ways. First, it fills the void in current CQ literature by providing a compelling theoretical support for the relationship between $\mathrm{CQ}$ and various expatriate effectiveness outcomes. Second, this article contributes to the expatriate literature by proposing a new set of individual differences (personality and CQ) which are distinct from and yet related to each other in conceptually meaningfully ways. Third, this article provides a comprehensive view on how CQ might be predicted and/or explained. Hence, by empirically examine the personality trait as the antecedent of CQ allows further understanding on how culturally intelligent individuals experience, interpret and make sense of their environments and the relationship between individual differences and factors of CQ. Significantly this article enrich the current expatriate literature by examining whether cross-cultural adjustment mediate the relationship between individual differences which is personality traits and CQ and expatriate job performance. The examination of a mediating role for adjustment may deepen our knowledge about a potential underlying mechanism that is responsible for the effects of personality traits and CQ on expatriates assignment effectiveness. This article theoretically explore the conceptual similarity of the CQ construct to other non-academic intelligences theoretically expected, or empirically shown, to relate to expatriate effectiveness such as EQ and SQ. Thus, we anticipate to begin to establish the conceptual uniqueness of $\mathrm{CQ}$ in relation to other non-academic intelligences in explaining expatriates cross-cultural adjustment and job performance. Finally, related to international human resource management, discussion on this article research may provide organizations with valuable direction and tools in the area of expatriate selection, placement and training and development. Although there are arguments that CQ can be trained, candidate with readily high CQ level definitely is more preferable and more likely to produce results than those low in CQ. We conclude by hoping for this research to stimulate more research attention on how CQ can enhance expatriate effectiveness in its broader nomological network by examining various antecedents, moderators and outcomes of CQ. 


\section{REFERENCES}

1. Ang, S., L. Van Dyne and S.K. Koh, 2006. Personality correlates of the four-factor model of cultural intelligence. Group Org. Manage., 31: 100-123. DOI: $10.1177 / 1059601105275267$

2. Van Dyne, .L., and S. Ang. (2006). A selfassessment of your CQ. In P.C. Earley, S. Ang, \& J.S.Tan. CQ: Developing cultural intelligence at work (pp. 217-227). Stanford, CA: Stanford University Press. ISBN 0804743134

3. Ang, S., L. Van Dyne, C. Koh, K.Y. Ng, K.J. Templer, C. Tay and N.A. Chandrasekar, 2007. Cultural Intelligence: Its measurement and Effects on Cultural Judgment and Decision Making, Cultural Adaptation and Task Performance. Manage. Org. Rev., 3: 335-371. DOI: 10.1111/j.1740-8784.2007.00082.x

4. Bandura, A., 2002. Social cognitive theory in cultural context. Applied Psychology: An Int. Rev., 51: 269-290. DOI: 10.1111/1464-0597.00092

5. Bandura, A., 1977. Social Learning Theory.1st Edn. Englewood Cliffs, NJ: Prentice Hall. ISBN 0138167443

6. Barrick, M.R. and M.K. Mount, 1991. The Big Five personality dimensions and job performance: A Meta-Analysis. Personnel Psychol., 44: 1-26. http://search.ebscohost.com.eserv.uum.edu.my/logi n.aspx?direct $=$ true $\& \mathrm{db}=$ buh $\& A N=9609192320 \&$ si te $=$ ehost-live \&scope $=$ site

7. Bhaskar-Shrinivas, P., D.A. Harrison, M.A. Shaffer and D.M. Luk, 2005. Input-based and time-based models of international adjustment: Meta-analytic evidence and theoretical extensions. Acad. Manage. $\quad$ J., $\quad 48$ : 259-281. http://search.ebscohost.com.eserv.uum.edu.my/logi n. aspx?direct=true $\& \mathrm{db}=$ buh $\& A N=16928400 \&$ site $=$ ehost-live \&scope $=$ site

8. Black, J.S., 1988. Work role transitions: A study of American expatriate managers in Japan. J. Int. Business $\quad$ Studies, 19: 277-294. http://proquest.umi.com/pqdweb?did=583122\&sid $=4 \& \mathrm{Fmt}=2 \&$ clientId $=36652 \& \mathrm{RQT}=309 \& \mathrm{VName}$ $=\mathrm{PQD}$

9. Black, J.S. and G.K. Stephens, 1989. The influence of the spouse on American expatriate adjustment and intent to stay in Pacific Rim overseas assignments. J. Manage., 15: 529-544. DOI: 10.1177/014920638901500403

10. Brislin, R., R. Worthley and B. MacNab, 2006. Cultural intelligence: Understanding behaviors that serve peoples goals. Group Org. Manage., 31: 40-55. DOI: $10.1177 / 1059601105275262$
11. Buss, D.M., 1991. Evolutionary personality psychology. In: Rosenzweig, M.R. and L.W. Porter (Eds.). Annu. Rev. Psychol., Palo Alto, CA: Annu. Rev. Inc., 42: 459-492. http://arjournals.annualreviews.org/loi/psych?cooki eSet $=1$

12. Caligiuri, P.M., 2000a. The Big Five personality characteristics as predictors of expatriates desire to terminate the assignment and supervisor-rated performance. Personnel Psychol., 53: 67-88. http://search.ebscohost.com.eserv.uum.edu.my/logi n. aspx ?direct $=$ true $\& \mathrm{db}=$ buh $\& A N=2919233 \&$ site $=$ ehost-live \&scope $=$ site

13. Caligiuri P.M., 1997. Assessing expatriate success: Beyond just being there. In: New approach. Employee Manage, Saunders. D.M. and Z. Aycan (Eds.). Greenwich, CT: JAI Press. 4: 117-140. ISBN: 0762300140

14. Caligiuri, P.M., 2000b. Selecting expatriates for personality characteristics: A moderating effect of personality on the relationship between host national contact and cross-cultural adjustment. Manage. Int. Rev., 40: 61-80. http://proquest.umi.com.eserv.uum.edu.my/pqdweb ?did $=52981545 \&$ sid $=1 \&$ Fmt $=2 \&$ clientId $=28929 \&$ $\mathrm{RQT}=309 \& \mathrm{VName}=\mathrm{PQD}$

15. Campbell, J.P., 1999. The definition and measurement of performance in the new age. In: Ilgen, D.R. and E.D. Pulakos (Eds.). The changing nature of performance: Implications for Staffing, Motivation and Development. San Francisco, Calif: Jossey-Bass: $\quad 399-429 . \quad$ ISBN: 0787946257 9780787946258

16. Cantor, N. and J.F. Kihlstrom, 1985. Social intelligence: The cognitive basis of personality. Rev. Personality Social Psychol., 6: 15-33. http://www.stormingmedia.us/23/2388/A238892.ht $\mathrm{ml}$

17. Carver, C.S. and M.F. Scheier, 2000. Perspectives on Personality (4th Edn.). Needham Heights, MA: Allyn and Bacon. ASIN: B001CD9906

18. Chen, G., S.M. Gully, J.A. Whiteman and B.N. Kilcullen, 2000. Examination of relationships among trait-like individual differences, state-like individual differencesand learning performance. J. App. Psychol., 85: 835-847. DOI: 10.1037/00219010.85.6.835

19. Cohen, S., 1980. Aftereffects of stress on human performance and social behavior: A Rev. Res. Theory. Psychol. Bull., 88: 82-108. http://search.ebscohost.com.eserv.uum.edu.my/logi n. aspx? direct $=$ true $\& \mathrm{db}=$ pdh \&AN=bul-88-182\&site $=$ ehost-live\&scope $=$ site

20. Dalton, M. and M. Wilson, 2000. The relationship of the five-factor model of personality to job performance for a group of Middle Eastern expatriate managers. J. Cross-Cultural Psychol., 31: 250-258. DOI: $10.1177 / 0022022100031002007$ 
21. Lievens, F., Harris, M.M., Van Keer, E., and Bisqueret, C. 2003. Predicting cross-cultural training performance: The validity of personality, cognitive ability, and dimensions measured by an assessment center and a behavior description interview, J. App. Psychol., 88(3): 476-489. DOI: 10.1037/0021-9010.88.3.476

22. Earley, P.C. and S. Ang, 2003. Cultural intelligence: Individual interactions across cultures. 1st Edn. Palo Alto: Stanford University Press. ISBN: 0804743126

23. Earley, P.C. and R.S. Peterson, 2004. The elusive cultural chameleon: Cultural intelligence as a new approach to intercultural training for the global manager. Acad. Manage. Learn. Edu., 3: 100-115. http://search.ebscohost.com.eserv.uum.edu.my/logi n.aspx? direct $=$ true $\& d b=$ buh $\& A N=12436826 \&$ site $=$ ehost-live\&scope $=$ site

24. Eccles, J.S. and A. Wigfield, 2002. Motivational beliefs, values, and goals. Annu. Rev. Psychol., 53:

109-132.

http://search.ebscohost.com.eserv.uum.edu.my/logi n.aspx?direct $=$ true $\& \mathrm{db}=\mathrm{a} 3 \mathrm{~h} \& \mathrm{AN}=6262852 \&$ site $=\mathrm{e}$ host-live\&scope $=$ site

25. Epel, E.S., A. Bandura and P.G. Zimbardo, 1999. Escaping homelessness: The influences of selfefficacy and time perspective on coping with homelessness. J. Applied Social Psychol., 29: 575-596. DOI: $10.1111 /$ j.15591816.1999.tb01402.x

26. Goffman, E., 1959. The presentation of self in everyday life. Harmondsworth: Penguin. ISBN 0385094027

27. Gregersen, H.B. and J.S. Black, 1990. A multifaceted approach to expatriate retention in international assignments. Group Org. Studies, 15: 461-485. DOI: 10.1177/105960119001500409

28. Gudykunst, W.B., S. Ting-Toomey and E. Chua, 1988. Culture and interpersonal communication. 1st Edn .Newbury Park, Calif: Sage. ISBN 0803929455

29. Hall, E.T., 1993. The anthropology of everyday life. 1st Edn .New York: Anchor Books. ISBN 0385237448

30. Hechanova, R., T.A. Beehr and N.D. Christiansen, 2003. Antecedents and consequences of employees adjustment to overseas assignments: A MetaAnalytic Review. Appl. Psychol., 52: 213-236. http://search.ebscohost.com.eserv.uum.edu.my/logi n.aspx?direct $=$ true $\& \mathrm{db}=\mathrm{a} 3 \mathrm{~h} \& \mathrm{AN}=9267415 \&$ site $=\mathrm{e}$ host-live \&scope $=$ site

31. Hogan, J. and B. Holland, 2003. Using theory to evaluate personality and job-performance relations: A socioanalytic perspective. J. Applied Psychol., 88: 100-112. DOI: 10.1037/00219010.88.1.100
32. Hogan, R. and B.W. Roberts, 2000. A socioanalytic perspective on person-environment interaction. In: Walsh, W.B., K.H. Craik and R.H. Price (Eds.). Person-environment psychology: New directions and perspectives (2nd Ed.). Mahwah, NJ: Erlbaum. pp: 1-23. ISBN 0805824715

33. Hogan, R. and D. Shelton, 1998. A socioanalytic perspective on job performance. Human Performance. 11: 129-144. http://search.ebscohost.com.eserv.uum.edu.my/logi n.aspx?direct $=$ true $\& d b=$ buh $\& A N=7309085 \&$ site $=$ ehost-live\&scope $=$ site

34. Hurtz, G.M. and J.J. Donovan, 2000. Personality and job performance: The Big Five revisited. J. Appl. Psychol., 85: 869-879. DOI: 10.1037/00219010.85.6.869

35. Jun, S. and J. Gentry, 2005. An exploratory investigation of the relative importance of cultural similarity and personal fit in the selection and performance of expatriates. J. World Business, 40: 1-8. DOI:10.1016/j.jwb.2004.10.001

36. Kanfer, R., 1990. Motivation theory and industrial/organizational psychology. In: Dunnette, M.D. and L. Hough (Eds.). Handbook of industrial and organizational psychology. Theory in industrial and organizational psychology .Palo Alto, CA: Consulting Psychologists Press. 1: 75170. ISBN: 0891060448

37. Kanfer, R. and P. Ackerman. 2001. Individual Differences in Work Motivation: Further Explorations of a Trait Framework, App. Psych. 49: 470 - 482. DOI: 10.1111/1464-0597.00026

38. Katz, D. and R.L. Kahn, 1978. The Social Psychology of Organizations. 2nd Edn., Wiley, New York: ISBN 0471023558

39. Janssens, M., and J.M., Brett, 2006. Cultural intelligence in global teams: A fusion model of collaboration. Group and Organization Manage., 31: 124-153. DOI: 10.1177/1059601105275268

40. Kim, K. and J.W. Slocum, 2008. Individual differences and expatriate assignment effectiveness: The case of U.S.-based Korean expatriates. J. World Business, 43: 109-126. DOI:10.1016/j.jwb.2007.10.005

41. Kraimer, M.L. and S.J. Wayne, 2004. An examination of perceived organizational support as a multinational construct in the context of an expatriate assignment. J. Manage., 30: 209-237. DOI: 10.1016/j.jm.2003.01.001

42. Kraimer, M.L., S.J. Wayne and R.A. Jaworski, 2001. Sources of support and expatriate performance: The mediating role of expatriate adjustment. Personnel Psychol., 54: 71-99. http://search.ebscohost.com.eserv.uum.edu.my/logi n.aspx?direct $=$ true \&db $=$ buh $\& A N=4229448 \&$ site $=$ ehost-live \&scope $=$ site 
43. Lee, L.Y. and B.M. Sukoco, 2007. The effects of expatriate personality and cultural intelligence on the expatriate adjustment: The moderating role of expatriate. In: Proceedings of the 13th Asia Pacific Management Conference (pp. 922-931), Melbourne, Australia, November 18-20. http://infotech.monash.edu.au/research/centres/cdse sr/apmc/papers-pdf/t070.pdf

44. MacDonald K., 1998. Evolution, culture, and the five-factor model. J. Cross-Cultural Psychol., 29: 11 9-149. DOI: 10.1177/0022022198291007

45. Motowidlo, S.J., J.S. Packard and M.R. Manning, 1986. Occupational stress: Its causes and consequences for job performance. J. Appl. Psychol., 71:618-629. DOI: 10.1037/00219010.71.4.618

46. Nicholson, N., 1984. A theory of work-role transitions. Administrative Sci. Q., 29: 172-191. http://search.ebscohost.com.eserv.uum.edu.my/logi n. aspx? direct=true $\& d b=$ buh $\& A N=3991723 \&$ site $=$ ehost-live \&scope $=$ site

47. Ones, D. and C. Viswesvaran, 1999. Relative importance of personality dimensions for expatriate selection: a policy capturing study. Human Performance, 12: 275-90. http://search.ebscohost.com.eserv.uum.edu.my/logi n. aspx ?direct $=$ true $\& \mathrm{db}=$ buh $\& A N=3344631 \&$ site $=$ ehost-live \&scope $=$ site

48. Osman-Gani, A.M. and T. Rockstuhl, 2008. Antecedents and consequences of social network characteristics for expatriate adjustment and performance in overseas assignments: Implications for HRD. Human Resour. Develop. Rev., 7: 32-57. DOI: $10.1177 / 1534484307312182$

49. Parker, B. and G.M. McEvoy, 1993. Initial Examination of a Model of Intercultural Adjustment. Int. J. Intercultural Relat., 17: 355-79. DOI:10.1016/0147-1767(93)90039-B

50. Sternberg, R.J., and E.L. Grigorenko, 2006. Cultural intelligence and successful intelligence. Group and Org. Manage., 31: 27-39. DOI: $10.1177 / 1059601105275255$

51. Salovey, P. and J.D. Mayer, 1990. Emotional intelligence. Imagination, Cognition and Personality, 9: 185-211. http://www.unh.edu/emotional_intelligence/EI\%20 Assets/Reprints...EI\%20Proper/EI1990\%20Emotio nal\%20Intelligence.pdf
52. Searle, W. and C. Ward, 1990. The prediction of psychological and sociocultural adjustment during cross-cultural transitions. Int. J. Intercultural Relat., 14: 449-464. DOI: 10.1016/0147-1767(90)90030$\mathrm{Z}$

53. Shaffer, M.A., D.A. Harrison, H. Gregersen, J.S. Black and L.A. Ferzandi, 2006. You can take it with you: Individual differences and expatriate effectiveness. J. Appl. Psychol., 91: 109-125. DOI: 10.1037/0021-9010.91.1.109

54. Shay, J.P. and S. Baack, 2006. An empirical investigation of the relationships between modes and degree of expatriate adjustment and multiple measures of performance. Int.. J. Cross Cultural Manage., 6: 275-294. DOI: $10.1177 / 1470595806070634$

55. Sinangil, H. K. 2004. Globalisation and Managing Organisational Culture Change: The Case of Turkey. Psych. \& Dev. Soc. 16 : 27-40. DOI: 10.1177/097133360401600102

56. Stone-Romero, E., D.L. Stone and E. Salas, 2003. The influence of culture on role conceptions and role behavior in organizations. Applied Psychology: An Int. Rev., 52: 328-362. DOI: 10.1111/1464-0597.00139

57. Takeuchi, R., S. Yun and P.E. Tesluk, 2002. An examination of crossover and spillover effects of spousal and expatriate cross-cultural adjustment on expatriate outcomes. J. Applied Psychol., 87: 655-666. DOI: 10.1037//0021-9010.87.4.655

58. Templer, K.J., C. Tay and N.A. Chandrasekar, 2006. Motivational cultural intelligence, realistic job previewsand realistic living conditions previewand cross-cultural adjustment. Group Org. Manage., 31: 154-173. DOI: $10.1177 / 1059601105275293$

59. Triandis, H.C., 1994. Culture and Social Behavior. New York: McGraw Hill. ISBN: 0070651108 (007-065110-8)

60. Vicino, F.L. and B.M. Bass, 1978. Lifespace variables and managerial success. J. Applied Psychol., 63: 81-88. DOI: 10.1037/00219010.63.1.81

61. Wang, M. and R. Takeuchi, 2007. The role of goal orientation during expatriation: A cross-sectional and longitudinal investigation. J. Appl. Psychol., 93: $1437-1445 . \quad$ DOI: $10.1037 / 0021-$ 9010.92.5.1437 